\title{
Precision Density Measurement of Silicon ${ }^{12}$
}

\author{
Ivars Henins ${ }^{3}$
}

(June 10, 1964)

\begin{abstract}
The densities of 22 large highly perfect silicon single crystals have been measured by hydrostatic weighing in water, yielding an average value of

$$
d_{\mathrm{Si}}\left(25^{\circ} \mathrm{C}\right)=2.329002 \pm\left(7 \times 10^{-6}\right) \mathrm{g} / \mathrm{cm}^{3} .
$$

An experimental precision has been achieved which exceeds the accuracy with which the absolute density of water is known. The effect of variations of the water surface tension force on the suspension wire has been mimized by using a 0.001 in. suspension wire coated with platinum black, and by doing a large number of repeated weighings of each crystal.
\end{abstract}

\section{Introduction}

Measurement of density is one of the most basic of physical measurements, and is often intrinsic in the determination of other physical constants. For instance, the density together with the lattice spacing and molecular weight of a crystal can be used to determine Avogadro's number [1]. ${ }^{4}$ Similarly, it is possible to determine relative atomic or molecular weights from the densities and lattice constants of different crystals [2]. Density has also been used as an indication of the lattice perfection of crystals [3]. In a different type of experiment, the density of a crystal has been used as a factor in determining $\mathrm{e} / \mathrm{m}$ of the electron from the index of refraction of $\mathrm{x}$ rays $[4]$.

One of the most direct methods of determining the density of solid bodies is by hydrostatic weighing in a liquid of known density, and conversely, the density of a liquid can be measured by hydrostatic weighing of a solid body of known mass and volume. Aside from the usual problems associated with precision weighing, the main difficulty encountered is due to the variation of the surface tension effects of the liquid on the suspension wire passing through the surface. These effects must be minimized by using minimum diameter suspension wire and by keeping a constant contact angle of the liquid against the wire.

This paper describes the procedure which has been used to measure the density of silicon crystals up to $18 \mathrm{~g}$ in size. Primary attention is paid to the apparatus and methods used for the hydrostatic weighing in water. In another paper [5] the result of this density determination has been used in conjunction with $\mathrm{x}$-ray lattice spacing measurements of the same crystals to determine the absolute scale of $x$-ray wavelengths.

1 This work was supported by the U.S. Atomic Energy Commission. 2 This paper is based in part on a doctoral dissertation submitted to the Department of Physies, The Johns Hopkins University, 1961.

3 Present address: Los A lamos Seientific Laboratory, University of California, Los Alamos, N. Mex.

${ }_{4}^{4}$ Figures in brackets indicate the literature references at the end of this paper.

\section{Experimental Procedure}

Accurate density measurement consists of a precise determination of the mass and the volume of an object. The mass can be determined by direct weighing, but the volume must usually be determined indirectly by determining the mass of water that the object displaces. Kohlrausch [6] was the first to use this method for accurate density determination, and it usually bears his name. The density, $d_{0}$, of the object of mass $M_{0}$, then is given by

$$
d_{0}=M_{0} d_{\mathrm{H}_{2} \mathrm{O}} /\left(M_{0}-M_{0 \mathrm{w}}\right)
$$

where $M_{0 w}$ is its apparent mass in water, and $d_{\mathrm{H}_{2} \mathrm{O}}$ the density of water at the time of weighing. Thus the accuracy of the density determination depends to a large extent on the accuracy of the weighings. This accuracy depends on the precision and sensitivity of the balance, the accuracy of the weights, and the care with which the weighings are made. A good discussion of the weighing process and the construction of precision balances has been presented by Corwin [7].

As already stated, the main difficulty with the weighings in water is due to the surface tension effects on the suspension at the liquid surface. The surface tension of water at $25^{\circ} \mathrm{C}$ against air is 71.97 $\mathrm{dyn} / \mathrm{cm}$. Thus if a $0.001 \mathrm{in}$. wire is wetted perfectly, the downward force on it due to surface tension is $0.574 \mathrm{dyn}$, which is equivalent to $586 \mu \mathrm{g}$ of weight. Since this force on the wire varies as the cosine of the liquid contact angle, it is desirable to maintain a nearly zero contact angle, thus minimizing the force variations due to small changes in the angle. In general, the contact angle varies with the cleanliness of the metal surface and with the direction of motion of the water surface. Usually, for a receding water surface, the contact angle is very nearly equal to zero [8]. Therefore the usual procedure in hydrostatic weighing has been to clean the suspension wire very carefully and to use exactly the same portion of the wire in each weighing [9]. It has also been 
suggested that the contact angle should be observed during the measurements to insure its constancy [10]. The associated problems of this method are that a zero contact angle is very difficult to attain, it depends on the direction of travel of the contact line relative to the metal surface, and minute traces of foreign matter on the metal surface will alter the contact angle considerably. On the other hand, the contact angle against a rough metal surface may be zero due to capillary attraction of the liquid to the surface. This fact was utilized in this experiment and has also been applied by various other observers who have coated their suspensions with either a rough gold [11] or platinum black [12] coating.

The following paragraphs describe the equipment and procedures used in this experiment.

\subsection{The Balance}

A Mettler M-5 microbalance was chosen for this experiment primarily because of its automatic weight changing feature and because it can be obtained with an under the pan weighing attachment. The capacity of this balance is $20 \mathrm{~g}$. The balance was enclosed in an additional sheet aluminum case to exclude air currents, and the experiment was performed in a room where the temperature was controlled to within $\pm 0.2^{\circ} \mathrm{C}$ of $25^{\circ} \mathrm{C}$.

Because the weights are housed inside the balance, and not easily removable, they were calibrated by weighing a set of National Bureau of Standards certified class $M$ weights [13]. The procedure for calculating the weight corrections from these weighing 3 has been developed by Lashof and Macurdy [14]. These calculations also yield (exclusive of the standard weight errors) the probable error of weighing with the balance. On this particular balance the probable error of a weighing was approximately $1 \mu \mathrm{g}$.

\subsection{Air Bouyancy Corrections}

Because of different densities of the object being weighed and of the weights, the buoyant force on the two may be different. The true mass, $M_{0}$, of the object then is given to a good approximation by

$$
M_{\mathrm{o}}=M_{w}+M_{w}\left(1 / d_{\mathrm{o}}-1 / d_{w}\right) \rho,{ }^{5}
$$

where $M_{w}$ is the true mass of the weights, $\rho$ is the density of air, and $d_{0}$ and $d_{w}$ the densities of the object and the weights respectively [16]. The density of air with the normal $\mathrm{CO}_{2}$ content of 0.04 percent by volume is given by [17]

$\rho=1.2930(273.15 / T)[(B-0.3783 \mathrm{e}) / 760] \times 10^{-3} \mathrm{~g} / \mathrm{ml}$,

\footnotetext{
${ }^{5}$ Using this approximate equation for calculating the mass of an object, the
error is only 0.18 parts per million in weighing silicon with stainless steel weights.
}

where

$e=$ vapor pressure of the water in air ( $\mathrm{mm} \mathrm{Hg})$, $T=$ absolute temperature $\left({ }^{\circ} \mathrm{K}\right) \quad\left[273.15{ }^{\circ} \mathrm{K}=0{ }^{\circ} \mathrm{C}\right]$ $B=$ barometric pressure $(\mathrm{mm} \mathrm{Hg})$.

Under normal atmospheric conditions each of the following variations will produce approximately one $\mu \mathrm{g} / \mathrm{cm}^{3}$ change in the density of air: $0.6-\mathrm{mm}$ change in barometric pressure, $0.2{ }^{\circ} \mathrm{C}$ change in temperature, and 7-percent change in relative humidity at $25{ }^{\circ} \mathrm{C}$. Obviously, the error that the uncertainties in the above quantities introduce in the weight determination, is proportional to the difference in volume of the object and the weights.

During this experiment, the air temperature was measured to $\pm 0.1{ }^{\circ} \mathrm{C}$ with a thermometer inserted inside the aluminum shroud of the balance. Later a thermistor thermometer [18] was constructed which could be inserted inside the balance case. The relative humidity was measured inside the balance case with an electrical resistance type hygrometer. The probable error in this measurement was estimated to be approximately 3 percent. The atmospheric pressure was measured to $\pm 0.2 \mathrm{~mm} \mathrm{Hg}$ probable error with an aneroid barometer which was calibrated against a mercury barometer.

\subsection{Density of Water}

Historically, water was chosen as the density standard because of its universal availability and because it was believed to have constant density. The International Prototype Kilogram was constructed to have as nearly as possible the mass of $1000 \mathrm{~cm}^{3}$ of water at its maximum density. Then the liter was defined as the volume of $1 \mathrm{~kg}$ of pure, air-free water at standard atmospheric pressure and at the temperature of its maximum density, approximately $4{ }^{\circ} \mathrm{C}$. It was left to experiment to determine the exact relationship between the liter and $1000 \mathrm{~cm}^{3}$.

The determination of the absolute density of water at any given temperature was carried out in two steps. First, the density relative to the maximum density was determined by Chappuis [19] and by Thiessen et al., [20] from measurements of thermal expansion. Tilton and Taylor [21] have recalculated the relative densities based on Chappuis' data. According to this recalculation, the density of water at $25^{\circ}$ relative to that at $4^{\circ}$ is $0.9970751 \mathrm{~g} / \mathrm{ml}$, and the change in density with temperature in the range from $25.0{ }^{\circ} \mathrm{C}$ to $25.1{ }^{\circ} \mathrm{C}$ is $-256 \times 10^{-6} \mathrm{~g} / \mathrm{ml}$ per ${ }^{\circ} \mathrm{C}$. The absolute density of water was determined in three very painstaking experiments by hydrostatic weighing of objects with known masses and volumes $[22,23,24]$. From these experiments it was determined [25] that 1 liter $=1000.028 \mathrm{~cm}^{3}$. Unfortunately at the time of the above experiments nothing was known about isotopes, and consequently, no precautions were taken to avoid isotopic fractionation during the distillation of the water. Chappuis makes the statement that his usual procedure was to redistill good quality commercially available 
distilled water [26]. In view of this, DuMond, Cohen, et al., have assigned to this value a probable error of $3 \mathrm{ppm}$ [27]. Even this error may be optimistic, and actually may be worse. Based on the above values, the absolute density of water at $25^{\circ} \mathrm{C}$ is $0.997047 \pm\left(3 \times 10^{-6}\right) \mathrm{g} / \mathrm{cm}^{3}$.

Natural waters from different parts of the world have been found to vary in density by only a few parts in ten million [28]. The effect of dissolved air on the density of water at $25{ }^{\circ} \mathrm{C}$ is also only a few parts in ten million [29]. However, because of bubble formation on surfaces, the air must be removed from the water before hydrostatic weighings can be made. The average compressibility of water at the pressure of 1 to $10 \mathrm{~atm}$, at $25^{\circ} \mathrm{C}$ is $47.6 \times 10^{-6}$ per atm [30].

For the present experiment ordinary tap water was triply distilled according to a procedure suggested by Bauer and Levin [31], and boiled before use to expel the absorbed air. 'The probable error in the density due to fractionation and the remaining impurities is estimated to be less than $1 \mathrm{ppm}$. The purity of the water was checked by conductivity measurements [32], which gave values as low as $1.1 \times 10^{-6}(\Omega \mathrm{cm})^{-1}$ and never exceeded $1.7 \times 10^{-6}$ $(\Omega \mathrm{cm})^{-1}$.

\subsection{Weighing Chamber}

The weighing chamber for this experiment consisted of a triple walled glass container as shown in figure 1 . The thermostating water from a constant temperature bath flowed at a rate of approximately 3 gal per minute around the inner chamber and returned via the outer jacket. The bath temperature was measured with two calibrated calorimeter type $\left(0.01{ }^{\circ} \mathrm{C}\right.$ divisions $)$ thermometers. The thermometers were calibrated for total immersion, but in these measurements they were only partially immersed. Therefore it was important to correct for the hydrostatic pressure difference on the thermometer bulbs. This pressure effect was measured to be $0.10^{\circ} \mathrm{C} / \mathrm{atm}$. No stem temperature corrections were necessary, because the room was maintained at the same temperature as the bath. The total probable error in the temperature determination in the weighing chamber is estimated to be $0.004{ }^{\circ} \mathrm{C}$, which corresponds to approximately 1 ppm error in the water density.

Because the crystals had flat faces, it was possible to support them on a simple stirrup made of $3 \mathrm{~mm}$ glass rod. The crystals could be lifted from this stirrup for the "empty" weighings by means of the lifter which was raised by thin nylon lines leading to the outside. Thus it was possible to check the repeatability of the weighings by doing a series of weighings without removing the crystal from the weighing chamber. In addition to this, the balance could be deflected magnetically, thus producing motion of the suspension wire through the water surface, thus making possible repeated weighings without arresting the balance. Repeatability indicated that the surface tension forces on the suspen-

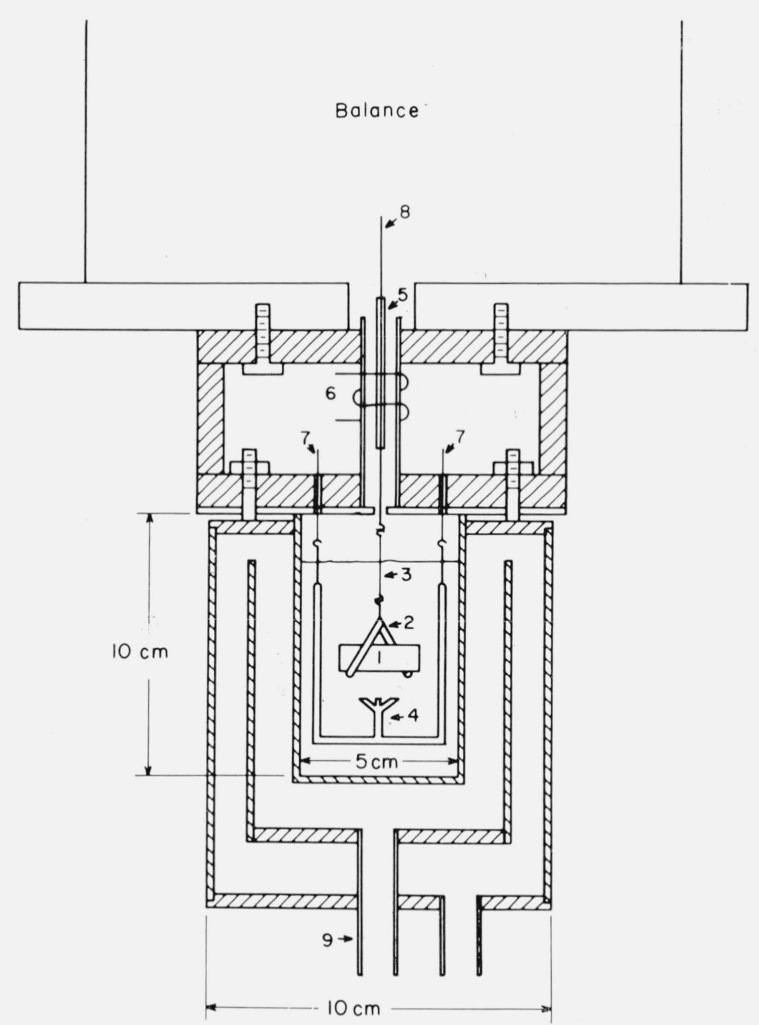

Figure 1. Details of the weighing chamber.

Legend: (1) crystal to be weighed, (2) crystal supporting 'stirrup, (3) suspension wire, (4) lifter for raising crystal from stirrup, (5) nickel wire spot welded to sion wire, (4) litter for raising crystal from stirrup, (J) nickel wire spot welded to support wire, (6) coil for magnetically deflecting the balance, (7) strings for raising
crystal lifter, (8) support wire attached to balance pan hook, and (9) inlet for crystal lifter, (8) sup
thermostating water.

sion were remaining constant. The most frequent problem encountered was due to small dust particles floating on the water surface attaching themselves to the suspension, and thus changing the effective diameter of the suspension. To eliminate errors from this, the weighings on each crystal were taken in several groups, the water level being lowered after each group of weighings. Weighings were continued until there was good agreement among the weighings in each group and among the averages of these groups.

\subsection{Preparation of the Suspension}

As already stated, the suspension wire passing through the water surface should be of minimum diameter to minimize the total surface tension force on it, its surface should be wetted by the water, and it should be easily replaceable. In this experiment, 0.001 in. diam 92 percent platinum, 8 percent tungsten alloy wire was used [35]. This wire is quite ductile and has a tensile strength of approximately 300,000 psi. Thus a 1 -mil diameter wire of this alloy will support approximately $100 \mathrm{~g}$ of weight. The hooks for the suspension wire were made by flattening the end of a short $(8 \mathrm{~mm})$ piece of $1-\mathrm{mm}$ diameter stainless steel wire and then filing a hook out of it. 
A longitudinal slot was cut in the body of the hook, the fine wire placed in the slot and then the slot crimped closed. First a hook was crimped onto one end of a $3-\mathrm{cm}$ long piece of the 1-mil wire. The wire was then cleaned in a sulfuric acid and sodium dichromate solution [38] and washed in distilled water. Next, the platinum black coating was applied from a plating solution of 3 -percent platinum chloride dissolved in 0.025-percent lead acetate solution [37]. A No. 18 platinum wire was used as the positive electrode and a $6-\mathrm{V}$ dry cell with a $1000 \Omega$ resistor in series supplied the current. The suspension wire was immersed up to the hook, and approximately $5 \mathrm{~mA}$ of current allowed to flow for $40 \mathrm{sec}$, with the wire being agitated to retard bubble formation. The coating should be even and uniformly rough and approximately $0.1-$ mil thick. This was verified by examination under a microscope of $200 \times$ magnification. If the coating was satisfactory, the suspension was again cleaned in the acid solution, washed in distilled water, and a hook crimped on the other end. This last cleaning was necessary because a freshly coated wire without cleaning did not exhibit a constant contact angle with the water surface.

\section{Experimental Results}

\subsection{Silicon Crystals}

A group of 22 large silicon single crystals ranging in weight from 5 to $18 \mathrm{~g}$ were available for this experiment [38]. These crystals were grown from high purity intrinsic silicon and had low dislocation densities, as specified by the suppliers. The main impurity was oxygen which varied in concentration from as low as $1.3 \times 10^{17}$ to as high as $8.8 \times 10^{17}$ atoms $/ \mathrm{cm}^{3}$. This was determined by measuring the infrared absorption at $9 \mu$ [39]. Before weighing, the crystals were ground to remove any foreign matter and jagged corners. Etching in $1: 3: 3$ solution (by volume) of $\mathrm{HF}, \mathrm{HNO}_{3}$, and glacial acetic acid for about $1 \mathrm{~min}$. removed any loose silicon particles from the surfaces. After being washed the crystals were kept under distilled water. Vacuum was applied to remove air bubbles from any small crevices.

\subsection{Density of Silicon}

The results of all the density determinations are shown in the form of a histogram in figure 2 . The average density at $25{ }^{\circ} \mathrm{C}$ was calculated to be

$$
d_{S \mathrm{i}}\left(25^{\circ} \mathrm{C}\right)=2.329002 \pm\left(7 \times 10^{-6}\right) \mathrm{g} / \mathrm{cm}^{3} .
$$

The probable error of this value consists of approximately $0.5-\mathrm{ppm}$ random error of the average, computed from $p=0.67\left[\Sigma_{i=1}^{k}\left(d_{i}-d_{a v}\right)^{2} /(k-1) k\right]^{\frac{1}{2}}$ and $3-\mathrm{ppm}$ systematic error in the water density. The individual density determinations had a random probable error of approximately $3 \mu \mathrm{g} / \mathrm{cm}^{3}$, as computed by combining the errors in the various quantities used in the density calculations. This high precision of

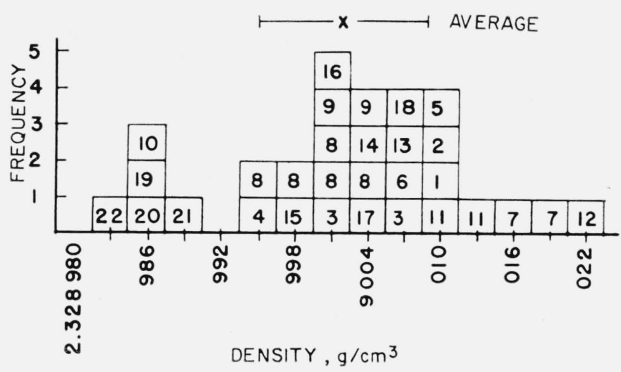

Figure 2. The density of silicon single crystals at $25{ }^{\circ} \mathrm{C}$.

Each square represents one independent density determination, and the numbers in the squares identify the crystals.

the experiment is also indicated in figure 2 by the close grouping of the density values obtained in separate measurements on the same crystals, such as, on crystals $3,7,8,9$, and 11 . Also crystals 19 , 20,21 , and 22 were obtained from the same source at the same time, and the close grouping of their densities indicates that they were probably cut from the same ingot.

Thus the variations in the densities of the different crystals are quite real, but so far, no correlation of these variations with any of the known properties of these crystals has been found. It has already been demonstrated by Smakula and Kalnajs [40] that the oxygen impurity does not affect the density of silicon. This is also indicated by the present results, although in this case, no really oxygen-free crystals were available for comparison.

The above density value can be compared to $d_{S 1}\left(25{ }^{\circ} \mathrm{C}\right)=2.32902 \pm\left(3 \times 10^{-5}\right) \mathrm{g} / \mathrm{cm}^{3}$ obtained by Smakula and Sils [9]. It also is in agreement with the lower precision value of $d_{S i}\left(25^{\circ} \mathrm{C}\right)=2.3289$ $\pm 0.0001 \mathrm{~g} / \mathrm{cm}^{3}$ obtained by Straumanis et al. [3]. It disagrees however, with an earlier measurement of $d_{S 1}\left(25^{\circ} \mathrm{C}\right)=2.3282 \pm 0.003 \mathrm{~g} / \mathrm{cm}^{3}$ by Straumanis and Aka [41].

\section{Conclusions}

In this experiment the density of silicon single crystals was measured by hydrostatic weighing with a precision of approximately one part per million. This high precision is due to the following factors: (a) the precision of the balance and an accurate calibration of the weights; (b) accurate water temperature control and measurement; (c) the platinumblack coated small diameter suspension wire, and (d) the ease with which repeated weighings could be made, thus making it possible to detect any erratic behavior of the surface tension effects on the suspension. At the present this precision exceeds the accuracy with which the absolute density of water is known, therefore it may be worthwhile to redetermine the absolute density of water with known isotopic composition. 
The densities of the invididual crystals showed variations which were larger than the experimental precision. However, the average of all these values should be a good indication of the true density of silicon. This average value agrees quite well with the precision measurement by Smakula and Sils [9].

This work was done under the direction of Professor J. A. Bearden, and the author wishes to express appreciation for his advice and assistance. The cooperation of Dr. W. C. Dash of General Electric Company, Dr. Morris Tanenbaum of the Bell Telephone Laboratories, and Dr. Walter Runyan of Texas Instruments, Inc., in providing the crystals is greatly appreciated. Also the author is indebted to Mr. L. B. Macurdy and Mr. J. F. Swindells of the National Bureau of Standards for providing the certified weights and the calibration of the thermometers.

\section{References and Notes}

[1] R. T. Birge, Am. J. Phys. 13, 69 (1945).

[2] H. L. Johnston, D. A. Hutchison, Phys. Rev, 62, 32 (1942); D. A. Hutchison, J. Chem. Phys. 13, 383 (1945).

[3] A. Smakula, J. Kalnajs, V. Sils, Phys. Rev. 99, 1747 (1955) ; M. E. Straumanis, P. Borgeaud, W. J. James, J. Appl. Phys. 32, 1382 (1961).

[4] J. A. Bearden, Phys. Rev. 54, 698 (1938).

[5] I. Henins and J. A. Bearden, in press.

[6] F. Kohlrausch and W. Hallwachs, Wied. Ann. d. Phys. 50, 118 (1893).

[7] A. H. Corwin, in Physical Methods of Organic Chemistry, 3d ed., Part I, p. 71, A. Weissberger, ed. (Interscience Publishers, Inc., New York, 1959).

[8] F. E. Bartell and J. T. Smith, J. Phys. Chem. 5\%, 165 (1953); D. J. Trevoy and H. Johnson Jr., J. Phys. Chem. 62, 833 (1958).

[9] A. Smakula and V. Sils, Phys. Rev. 99, 1744 (1955).

[10] W. Primak, Rev. Sci. Instr. 29, 177 (1958).

[11] P. Hidnert and E. L. Peffer, NBS Circular No. 487 (U.S. Government Printing Office, 1950).

[12] O. Redlich and J. Bigeleisen, J. Am. Chem. Soc. 64, 758 (1942)

[13] The writer is indebted to L. B. Macurdy of the National Bureau of Standards for the loan of these weights, and for a very enlightening discussion of precision weighing.

[14] T. W. Lashof and L. B. Macurdy, Analytical Chemistry 26, 707 (1954).

[15] T. W. Lashof and L. B. Macurdy, NBS Circular No. 547, sec. 1 , p. 10 (1954).

[16] NBS Circular No. 3, 3d ed. (1918).

[17] F. W. J. Whipple, International Critical Tables (1928), vol. I, p. 71 .
[18] K. S. Cole, Rev. Sci. Instr. 28, 326 (1957).

[19] P. Chappuis, Trav. mém. bur. int. poids mes. 13, D1-D40 (1907)

[20] M. Thiessen, K. Scheel, and H. Diesselhorst, Wiss. Abh. phys.-techn. Reichsanst. 3, 1-70 (1900).

[21] L. W. Tilton and J. K. Taylor, J. Res. NBS 18, 205 (1937) RP 971

[22] C. E. Guillaume, Trav. mém. bur. int. poids mes. 14, A1-A276 (1910).

[23] P. Chappuis, Trav. mém. bur. int. poids mes. 14, B1-B163 (1910).

[24] J. Mace de Lepinay, H. Buisson, and J. R. Benoit, Trav. mém. bur. int. poids mes. 14, C1-C127 (1910).

[25] C. E. Guillaume, La Creation du Bureau Int. des Poids et Mes. (Gauthier-Villars, Paris, 1927), 256.

[26] P. Chappuis, Trav. mém. bur. int. poids mes. 14, D46 (1910).

[27] J. W. M. DuMond, E. R. Cohen, and K. M. Crowe, The Fundamental Constants of Physies, p. 5 (Interscience Publishers, Inc., New York, 1957).

[28] C. H. Greene and R. J. Voskuyl, J. Am. Chem. Soc. 61, $1342(1939)$

[29] W. Marek, Ann. d. Physik (3) 44, 171 (1891).

[30] N. E. Dorsey, Properties of Ordinary Water Substance, p. 243 (Reinhold Publishing Corp., New York, 1940).

[31] N. Bauer and S. Z. Levin, in Physical Methods of Organic Chemistry, A. Weissberger, ed., vol. I, part I, p. 136 (Interscience Publishers, Inc., New York, 1959).

[32] According to I. Kirshenbaum (ref. 33) the conductivity of water sufficiently pure for analysis with $0.1 \mathrm{ppm}$ accuracy should be of the order of magnitude of $1 \times 10^{-6}$ $(\Omega \mathrm{cm})^{-1}$. Voskuyl (ref. 34) has found that a slight impurity which changed the conductivity from $1.2 \times 10^{-6}$ to $2.2 \times 10^{-6}(\Omega \mathrm{cm})^{-1}$ changed the density by $0.7 \mathrm{ppm}$.

[33] I. Kirshenbaum, Physical Properties of Heavy Water, pp. 295, 296 (McGraw-Hill Book Company Inc., New York 1951).

[34] R. J. Voskuyl, quoted by I. Kirshenbaum, op. cit., p. 295.

[35] The author wishes to thank the Sigmund Cohn Corp. of Mount Vernon, N.Y., for suggesting the use, and providing a length of this wire (their alloy No. 479).

[36] $35 \mathrm{ml}$ saturated sodium dichromate to 1 liter of $\mathrm{H}_{2} \mathrm{SO}_{4}$.

[37] "Platinizing solution" sold by A. H. Thomas Co., Philadelphia, $\mathrm{Pa}$.

[38] Most of these crystals were obtained previously by Professor J. A. Bearden for determining the feasibility of using silicon as a standard x-ray diffraction crystal. We are greatly indebted to the following individuals and laboratories for providing the crystals, and for the cooperation without which this study would have been severely limited: the late Dr. W. C. Dash, of the General Electric Co., for supplying four of the crystals, Dr. Morris Tanenbaum of the Bell Telephone Laboratories for six crystals, and to Dr. Walter Runyan of Texas Instruments, Inc., for ten of the crystals. In addition, two crystals were purchased from Knapic Electro-Physics, Inc., of Palo Alto, Calif.

[39] W. Kaiser and P. H. Keck, J. Appl. Phys. 28, 882 (1957).

[40] A. Smakula and J. Kalnajs, J. Phys. Chem. Solids 6, 46 (1958).

[41] M. E. Straumanis and E. Z. Aka, J. Appl. Phys. 23, 330 (1952).

(Paper 68A5-299) 